\section{Objeción de conciencia, profesión médica y proyecto sobre despenalización del aborto en Chile}

\author{
MAURICIO BESIO
}

\section{Conscientious objection and the values of medical profession}

It is usual to understand conscientious objection as a doctor's refusal to perform a legitimate intervention, for subjective personal reasons unrelated to medicine. It is then accepted only by respect to professional autonomy and freedom of beliefs. Understood in that way it would be thus reasonable to limit it, curtail it or delete it, since the objector would not be willing to grant benefits that correspond to his medical profession. This work aims to show exactly the opposite, taking as an example the project of law that pretends to decriminalize abortion in some situations in Chile. Is the objector who defends medical activity relying on ethic codes that seek to preserve the values and principles of our profession.

(Rev Med Chile 2016; 144: 377-381)

Key words: Abortion, Legal; Abortion, Induced; Abortion Therapeutic; Bioethics; Codes of Ethics; Professionalism.
División de Obstetricia y

Ginecología, Unidad Docente

Asociada de Bioética. Facultad de

Medicina. Pontificia Universidad

Católica de Chile.

Departamento de Ética. Colegio

Médico de Chile A.G. Comisión

de Ética. Sociedad Chilena de

Obstetricia y Ginecología.

Recibido el 8 de septiembre de 2015, aceptado el 26 de diciembre de 2015 .

Correspondencia a:

Dr. Mauricio Besio Rollero

Av. Libertador Bernardo

O'Higgins 340, Santiago, Chile.

Teléfono: 223543048

Besio@med.puc.cl

\section{A} raíz del intenso debate que se ha suscitado en el país, en el ambiente médico y específicamente en el Departamento de Ética del Colegio Médico por el proyecto de ley sobre despenalización del aborto ${ }^{1}$, han surgido interesantes discusiones, entre las cuales destaca el tema de la objeción de conciencia. Ha sido relevante discernir la pertinencia de los objetores de conciencia en la eventual aprobación de este proyecto de ley que busca (aparentemente) una despenalización, pero con una mantención de la ilegitimidad de la acción abortiva en las tres causales que señala. Sólo la legalización es la que justificaría la existencia de la objeción de conciencia frente a la petición de un aborto.

Independientemente de la relevancia del punto anterior, ha sido interesante el intercambio de opiniones respecto del real ámbito de ejercicio de la objeción de conciencia del médico, en el caso de ser aprobado este proyecto. Surge la pregunta sobre los límites de la objeción y sobre la responsabilidad del médico objetor frente al sujeto solici- tante de la prestación, y sobre el acceso que tendría que tener la solicitante a prestaciones legitimadas.

\section{Objeción de conciencia y código de ética}

El código de ética de nuestra agrupación señala en su artículo $20^{2}$ "el médico a quien se solicitaren prestaciones que vayan en contra de su conciencia o de su convencimiento clínico, podrá negarse a intervenir. En estas circunstancias, procurará que otro colega continúe asistiendo al paciente, salvo que ello produjere graves e inmediatos daños para la salud del enfermo".

La existencia de este artículo en nuestro código de ética -que permite negarnos a realizar alguna intervención solicitada por un sujeto- nos interpela en primer lugar sobre las razones para que exista en ese cuerpo normativo que guía nuestro adecuado quehacer profesional. No deja de llamar la atención que en muchos códigos deontológicos médicos existe esa excepción. Para entenderla, 
será necesario remontarnos a hechos que, siendo fundamentales para nuestra actividad, caen en el olvido, repitiéndose así en los articulados de los códigos sin su justificación explícita.

En algunas actividades u oficios se exige a los que las practican un comportamiento que va más allá de lo que se les demanda como simples ciudadanos. Son ellas las llamadas profesiones, las cuales por sus especiales características requieren de un cuerpo normativo especial, dependiendo de los fines y responsabilidades que poseen. El concepto de "profesar" incluye, según la Real Academia Española (RAE) el de "ejercer algo con inclinación voluntaria”, de allí su carácter moral. En ellas existe un auténtico compromiso, tanto intelectual como emocional, con la acción que se realiza. Es por esta razón que las profesiones no son el mero ejercicio de un oficio, sino la completa entrega de una persona a su quehacer y con el rol que ésta cumple en la sociedad, instaurando para ello valores y principios que la caracterizan distintivamente y establecen los rasgos propios de los que la ejercen. Las profesiones entonces, manifiestan explícitamente estas máximas a través de códigos que exponen las conductas ideales a seguir, restringiendo al mismo tiempo las indeseables. Esta manifestación pública de principios es, al parecer, una característica propia de las profesiones. No es de extrañar entonces que la etimología más profunda de "profesar" remita a "profeso", participio pasivo del verbo latino profiteri, declarar.

\section{Profesión médica}

Lo que declara y a lo que se compromete a cumplir un médico está contenido en todos los juramentos, oraciones y códigos desde que la medicina se estableció como actividad propia, separándose de la mera superstición, de la religión y de la filosofía en el siglo $\mathrm{V}$ a. $\mathrm{C}^{2}$. Esto es la búsqueda de un bien particular del ser humano, su salud, entendida ella como una perfección entitativa que le corresponde naturalmente y que por alguna razón no posee, por haberla perdido o por no haberla poseído nunca ${ }^{3}$.

La medicina es entonces un saber práctico, cuyo objeto es la salud de los pacientes. Busca provocar un efecto o cambio en un sujeto solicitado explícita o implícitamente y que entendemos como salud.
Es cierto que el médico es requerido en numerosas ocasiones para labores que es capaz de realizar, pero que no corresponden exactamente a su quehacer primario (peritajes, investigación, auditorías etc.) y no pocas veces a otras que colisionan violentamente con su profesión (las que vulneran la integridad física, psicológica y espiritual de los pacientes).

A las primeras debe responder sin vulnerar su obligación "profesada" y las segundas debe rechazar.

Muchas veces esta tensión entre las obligaciones "inmanentes" y aquellas solicitadas por la sociedad, que requiere sus conocimientos y destrezas pero que no corresponden estrictamente al objeto de la profesión, permite, al ser ellas razonables, una adecuada regulación por los colegios profesionales y adaptaciones de los códigos de ética. Otras veces vulneran tan radicalmente lo que los médicos hemos procurado defender, que no es posible aceptarlas, ya que de permitirlo cambiaríamos el objeto de nuestro quehacer. Estas solicitudes han sido tan fuertes que han logrado incluso modificar los juramentos y códigos deontológicos, al no ser los médicos capaces de resistir esa presión ${ }^{4}$.

\section{Sentido de la objeción de conciencia del médico}

Teniendo presente lo previamente dicho, intentaremos analizar el verdadero "espíritu" del artículo 20 de nuestro código de ética y por ende de artículos similares en otros códigos deontológicos. Si reflexionamos sobre las razones por las cuales un médico pudiera negarse a realizar un procedimiento, veremos que todas ellas tienen un rasgo común: puede que el profesional no se sienta capacitado técnicamente para hacerla; puede ser también que no esté convencido del resultado de ella, o que juzgue que los riesgos son muy altos, o pudiera ser también a su juicio una intervención desproporcionada. Estas razones, que pueden ser consideradas razones técnicas, si las examinamos con mayor detención veremos que son más bien razones éticas. En efecto, si el médico se siente incapaz de realizarla, sería imprudente que lo hiciera, ya que puede causar al sujeto un daño. Si no está convencido del resultado o considere mucho riesgo o desproporción, también percibe que puede causar un daño más que un beneficio. 
Este rasgo común descansa en un principio ético fundamental y único: el médico busca el bien de su paciente y procura no dañarlo, y precisamente ese es el rasgo común que tienen todas las razones por la cuales un médico se niega finalmente a implementar una intervención.

Ahora bien, pareciera que existen otras razones que ya no tienen que ver con su "convencimiento clínico" sino que son de otro orden, surgido de una dimensión personal, íntima y particular de él, que no sería generalizable a todos, sino que más bien una excepción, pero que no pertenece estrictamente a la medicina sino que a la "conciencia" personal de ese individuo que está ejerciendo en este caso la actividad médica. Esa dimensión o conciencia particular le impediría responder a una petición, independientemente de considerar si esa intervención solicitada le pueda causar un daño o beneficio al solicitante. Serían consideraciones entonces fuera de la medicina, que no consideran los principios que la guían. Existirían médicos que, poseyendo alguna característica particular, estarían dispuestos a comportarse en contra o por lo menos fuera de los principios de beneficiencia y no maleficiencia que guían nuestro actuar con distintas expresiones, desde tiempos inmemorables.

Aceptar lo anterior sería extraño. No parece razonable que códigos de ética que pretenden establecer normas de conducta, basados en los principios que guían la profesión médica, permitan que un asociado se niegue a una petición de un paciente, con absoluta prescindencia de los daños o beneficios para el solicitante. La alusión a la conciencia como excepción para establecer una intervención debe tener otra explicación que la haga plausible.

Me parece que esa explicación nace justamente de la necesidad de explicitar, de declarar, de profesar lo que es la actividad médica. De clarificar a los demás que esta actividad se dedica a algo definido, que todos los afanes de los que prometen dedicarse a ella, están destinados a algo muy específico y nada más. Que su actividad tiene entonces límites, algunos poco claros, que permiten un actuar cuidadoso, y otros que no se deben traspasar. Esta declaración es necesaria por ser el médico poseedor de conocimientos y destrezas que pueden servir a muchos otros fines, y que pueden interesar a la sociedad por diversos motivos. Pero la declaración y la profesión señalan el objeto y los límites de la actividad. Diversos intereses sociales cambiantes intentarán modificar esos objetivos y límites, y probablemente siempre surgirán peticiones respaldadas incluso por normativas legitimadas por mayorías democráticamente ungidas, que buscarán intervenciones que atentarán absolutamente contra los fines y límites de la profesión ${ }^{5}$.

La invocación a la conciencia del médico no se refiere a aceptar la negativa de este profesional por razones personalísimas, particulares y subjetivas. La excepción está dada en todos los códigos de ética para otra cosa; para proteger a los médicos de peticiones respaldadas incluso por autoridades legítimas y que van en contra de lo profesado. Es un espacio para que un facultativo pondere si lo solicitado contraviene gravemente los objetivos de la profesión, decida de acuerdo con ello y sea apoyado por las agrupaciones que deben proteger sus valores. En definitiva, para que pueda rechazar responsablemente las peticiones que van claramente en contra de la beneficiencia y no maleficiencia debida a las personas a su cuidado. El rechazo a alguna petición por ir en contra de la conciencia del médico, es provocado por el juicio que éste realiza, al tomar conciencia que la petición vulnera algún valor de su profesión, valor asumido e interiorizado libremente al decidir dedicarse a la medicina. No es por vulnerar un principio propio, personalísimo, ajeno a la medicina, aunque pudieran coincidir. Actúa así para defender a sus pacientes y a la profesión.

Si nos fijamos en la literatura médica, los únicos ejemplos de una negativa válida para realizar una intervención, son aquellos relacionados con una estimación de mayor riesgo de daños al paciente frente a los beneficios buscados, y con las que atentan contra valores trascendentes de un paciente como el respeto a su vida e integridad, valores defendidos clásicamente por la medicina ${ }^{6-8}$.

¿Y la autonomía? Es cierto que es el paciente bien informado quien debe decidir sobre las intervenciones propuestas por el tratante. El médico no impone, pero tampoco es un mero ejecutor de las peticiones de sus pacientes, no debe aceptar realizar una intervención si juzga que va en contra de los principios de su actividad. Habitualmente, en una adecuada relación médico-paciente, se buscan las alternativas aceptables para ambos. Es posible que en algunas situaciones se mantenga un desacuerdo y finalmente se rompa esa relación. Es ésta una prerrogativa defendida universalmente 
por los códigos de ética y que ratifica que la actividad tiene principios propios y límites de su actuar.

El objetor ¿es injusto? no es así, ya que la justicia en la atención de la salud no es sólo del resorte del médico. El acceso oportuno, la disponibilidad, el costo razonable dependen de toda una estructura sanitaria que otros deben poner al servicio de un paciente. Además, el médico verdaderamente objetor no pretende obstruirle el acceso a lo que legalmente le corresponde. Es el sistema que al legitimar ciertas intervenciones susceptibles de objeción, debe responsabilizarse de garantizar el acceso a ellas.

\section{Responsabilidad del médico objetor}

Queda ahora intentar dilucidar, a la luz de lo expuesto anteriormente, la segunda parte del artículo 20 del código de ética. ¿Qué sucede cuando el médico decide no realizar una intervención solicitada por ir en contra de su conciencia o convencimiento clínico?

En primer lugar es preciso señalar que el médico en esta situación, no se niega a atender a su paciente. Lo único que rechaza es una prestación, y la rechaza debido a que a su juicio no es un verdadero tratamiento. Si lo solicitado es una intervención juzgada como desproporcionada, es rechazado por el médico por ello. Si lo solicitado es una intervención destinada a causar la muerte del paciente, por su terminalidad y sufrimiento, tampoco es un tratamiento. Si el requerimiento es un aborto debido a un embarazo producto de una violación, esa intervención no es tratamiento para el trauma sufrido. Y ese feto también está bajo el cuidado del médico.

Lo normal es que el médico rehúse realizar esas acciones porque no son intervenciones que busquen la salud, y además algunas de ellas atentan absolutamente contra el derecho a la vida de un paciente que está bajo su cuidado.

El médico debe estar siempre dispuesto a tratar a esos pacientes. Estará dispuesto, con toda la ayuda que sea necesaria, a otorgar los tratamientos proporcionados, a implementar los cuidados paliativos, a tratar a la mujer víctima de una violación, a tratar las patologías manejables del embarazo y a otorgar cuidados paliativos perinatales. Más aún, no dudará en interrumpir un embarazo cuando exista riesgo verdadero de muerte materna, y lo hará cumpliendo cabalmente los fines de la medicina, intentando salvar a sus dos pacientes.

Por último sólo resta explicar el sentido de la obligación de "procurar", es decir, en el caso de negarse a realizar la intervención, procurar que otro colega continúe su atención. Se suele entender que este procurar significa que el médico que no está dispuesto a realizar una intervención debe "facilitar", "conseguir", "poner en contacto" al paciente con otro colega que sí estaría de acuerdo en realizarla.

Esta interpretación, entendiendo que la objeción de conciencia se da cuando un médico se niega a intervenir, por considerar que esa acción violenta los principios médicos a los cuales se comprometió respetar, no tiene sentido. En efecto, si así fuera, tampoco podría hacerlo, ya que estaría participando activamente en esa acción y tendría que objetar nuevamente ${ }^{10}$. El sentido que tiene ese "procurar", es que el paciente no quede sin médico si se rompe la relación médico-paciente con la negativa. Recordemos que son pacientes que sí requieren de los cuidados que la medicina les puede brindar. Así aparece todo el sentido de la última frase del artículo: "salvo que ello produjere graves e inmediatos daños para la salud del enfermo". Claro, lo que busca la acción médica es evitar daños a la salud de los pacientes, y si el daño es inminente deberá atenderlo. Deberá intentar sacarlo de la situación de riesgo, aunque la relación entre ellos esté deteriorada, pero otorgándole verdaderos cuidados médicos. No tendría sentido enviar a ese paciente a un colega que sí le produzca algún daño, sería eso similar a hacerlos él mismo.

\section{Conclusión}

La medicina es una actividad con fines y principios que le otorgan su campo de responsabilidad y sus límites. Debe responder a los cambios sociales, adaptando para ello su quehacer, pero no puede renunciar a su objeto y a su responsabilidad primaria.

El verdadero sentido de los artículos en los códigos de ética que defienden la potestad del médico para no realizar alguna intervención, es la existencia de peticiones hacia estos profesionales que vulneran los fines y principios de su profesión, peticiones que muchas veces son respaldadas por 
leyes legitimadas democráticamente. A través de los tiempos los médicos y sus agrupaciones han intentado mantener esos fines y valores y por ello mantienen esa defensa en sus códigos de ética.

El olvido del verdadero sentido de la objeción de conciencia de un médico, permite que frente a los continuos ataques hacia los valores de la profesión médica, aparezca el objetor como un extraño que se debe tolerar en mayor o menor grado. La verdad es que es él, con su ejemplo, el que defiende esos valores y los que están de acuerdo en vulnerarlos, son los que tratan de limitar o coartar esa prerrogativa.

Agradecimientos: A todos mis colegas, miembros del Departamento de Ética del Colegio Médico de Chile A.G. Fue la fecunda discusión que se generó en su seno y los comentarios de cada uno de ellos, lo que motivó y enriqueció esta reflexión.

\section{Referencias}

1. Proyecto de ley que regula la despenalización de la interrupción del embarazo en tres causales. Mensaje 1230-362 de la Presidenta de la República de Chile a la Cámara de Diputados, enero de 2015. Disponible en http://www.minsegpres.gob.cl/wp-content/ upLoads/2015/01/1230-362-despenalia-interrupcion(Consultado el 25 de agosto de 2015).
2. Sobre la medicina antigua, Tratados hipocráticos. Madrid, España: Editorial Gredos; 1983, 12.

3. Sobre la ciencia médica 3, Tratados Hipocráticos. Madrid, España: Editorial Gredos; 1983, 3.

4. Código de Ética del Colegio Médico de Chile A.G. 2011. Disponible en http://www.colegiomedico.cl/wp-content/ uploads/2015/06/colmed_codigo_etica_2013.pdfcodigo_de_etica. (Consultado el 20 de agosto de 2015).

5. Código de Deontología Médica. Organización Médica Colegial, España. Disponible en: https://www.cgcom. es/sites/default/files/codigo_deontologia_medica.pdf. (Consultado el 26 de agosto de 2015).

6. Pellegrino D. Edmund. Some things ought never be done: moral Absolutes in clinical ethics. Theoretical Medicine and Bioethics 2005; 26: 469-86. Springer.

7. Besio M. Sobre el acto médico. Cuadernos de Bioética 2003; No 50. Vol. XIV, 1ª: 25-38.

8. Instituto Borja de Bioética. Grupo Interdisciplinario de Bioética. Bioética \& Debat 2012; 18 No 66: 3-12.

9. Beca JP, Atete C. Objeción de conciencia en la práctica médica. Rev Med Chile 2015; 143: 493-8.

10. Montero A, González E. La objeción de conciencia en la práctica clínica. Acta Bioethica 2011; 17 (1): 123-31.

11. Casas Becerra L, Dides Castillo C. Objeción de conciencia y salud reproductiva en Chile: dos casos paradigmáticos. Acta Bioethica 2007; 13 (2): 199-206.

12. Valderrama A, López R. Conciencia moral: ampliando su aplicación en salud. Aspectos teóricos y prácticos de los juicios de conciencia en Chile. Acta Bioethica 2011; 17 (2): 179-88. 